be the preferable instrument for following changes in airway resistance in consulting-room and bedside practice.

\section{Summary}

A comparison has been made using lung-function tests of three proprietary bronchodilator preparations given by dry metered aerosol to 24 patients with asthma and chronic bronchitis.

Isoprenaline sulphate $(1.20 \mathrm{mg}$.) was found to be the most effective preparation for the first 30 to 45 minutes after inhalation. Though orciprenaline $(2.25 \mathrm{mg}$.) was less effective in the short term, it proved superior to isoprenaline in having a substantial bronchodilator effect three hours after inhalation. There was, however, considerable individual variation in the response.

Bronchilator, a combination of three separate drugs (total dose $1.35 \mathrm{mg}$.), was less effective than either orciprenaline or isoprenaline in the above doses.

The peak-flow meter was found to give a more sensitive index of changes in airway resistance after bronchodilator drugs than a portable bellows spirometer. We conclude that the peak-flow meter provides the method of choice when a convenient portable instrument for following changes in airway resistance is required.
We wish to thank Bayer Products Company, Boehringer Ingelheim Ltd., and Riker Laboratories for supplies of the preparations and secretarial help, and Miss A. Chamney for technical assistance.

\section{REFERENCES}

Bouhuys, A. (1963). Ned. T. Geneesk., 107, 1739.

Edwards, G. (1964). Brit. med. 7., 1, 1015.

El-Shaboury, A. H. (1964). Ibid., 2, 1037.

Fairbairn, A. S., Fletcher, C. M., Tinker, C. M., and Wood, C. H. (1962). Thorax, 17, 168 .

Feinmann, L., and Newell, D. J. (1963). Brit. F. Dis. Chest, 57, 140

Goldfarb, A. A., and Romanoff, A. (1962). Ann. Allergy, 20, 307.

Günthner, W. (1961). Arzneimittel-Forsch., 11, 525.

Herschfus, J. A., Bresnick, E., Levinson, L., and Segal, M. S. (1951). Ann. Allergy, 9, 769.

Higgins, I. T. T. (1957). Brit. med. ₹., 2, 1198.

Higgins, I. T. T. (1957). Brit. med. F., 2, 1198.

Horton, G. E., and Phillips, S. (1959). Amer. Rev. resp. Dis., 80,

Jennedy, M. C. S., and Jackson, S. L. O. (1963). Brit. med. F., 2, 1506.

Lands, A. M., Luduena, F. P., Hoppé, J. O., and Oyen, I. H. (1958). f. Amer. pharm. Ass. sci. Ed., 47, 744.

Lewinsohn, H. C., Capel, L. H., and Smart, J. (1960). Brit. med. fo, 1,

Lockhart, W., Smith, D. H., Mair, A., and Wilson, W. A. (1960). Ibid., $1,37$.

McKerrow, C. B., and Edwards, P. (1961). F. Amer. med. Ass., 177, 865.

Myers, W. H., and Coltman, R. S. (1963). Med. Dig. (Lond.), 8, 95

Ritchie, B. (1962). Lancet, $2,271$.

Ritchie, B. (1962). Lancet, 2, 271.

Siegel, C. (1962). f.-Lancet, 82, 461.

Wright, B. M., and McKerrow, C. B. (1959). Brit. med. F., 2, 1041.

Zidek, R. (1961). Therapiewoche, 11, 545.

\title{
Average Normal Values for the Forced Expiratory Volume in White Caucasian Males
}

\author{
J. E. COTES,* B.M., M.R.C.P. ; C. E. ROSSITER,* M.A., F.S.S. ; I. T. T. HIGGINS,*† M.D., M.R.c.P. \\ J. C. GILSON,* M.B., F.R.C.P.
}

Brit. med. F., 1966, 1, 1016-1019

The forced expiratory volume (F.E.V.) and other indices of ventilatory capacity have been measured and expressed as multiple regressions on age and height for healthy male subjects in many Western countries. The present paper reports the results of such an analysis for data obtained in the U.K. over the period 1957-64. The relationship is similar to others that have been reported. A number of these have therefore been combined to yield an overall regression which describes the average relationship of one second F.E.V. (F.E.V.. $)$ to age and height for healthy white Caucasian males in North-western Europe and North America. The relationship may be of use for predicting average normal values in communities where no direct measurements are available.

\section{Analysis of Some Data from the U.K.}

Using the apparatus described by McKerrow et al. (1960), members of this unit have measured the forced expiratory volume (F.E.V..$_{0.75}$ and F.E.V. ${ }_{1}$ ) and the forced vital capacity (F.V.C.) of men taken randomly from within defined communities in the United Kingdom and elsewhere. These surveys individually show that the F.E.V.s of smokers, after allowing for the effects of age, are less than those of non-smokers (Higgins, 1959). The F.E.V.s are also lower in those subjects who during the previous three years had persistent cough and phlegm and one or more chest illnesses severe enough to cause loss of time from work (Higgins et al., 1956).

We have now re-analysed the data for 405 men working in non-dusty occupations in three of these communities and one other, having first excluded all those who gave a history of chest illness or of undue breathlessness on exertion. In 113 subjects exclusion was made on the basis of an affirmative answer to either or both of two questions which are now included in the following form in the M.R.C. (1960) questionary on respiratory symptoms.

Question 21: During the past three years have you had any chest illness which has kept you off work, indoors, at home, or in bed ?

Question 14a: Are you ever troubled with shortness of breath when hurrying on the level or walking up a slight hill ?

Subjects who gave a negative response to these questions were not excluded on account of cough, sputum, or other symptoms except in nine instances when the symptoms were accompanied by a history of previous tuberculosis, pneumonia, or other notable chest illness. Eight subjects were excluded because their data were incomplete.

\footnotetext{
- Pneumoconiosis Research Unit of the Medical Research Council, Llandough Hospital, Penarth, Glamorgan.

t Present address: Department of Epidemiology, University of Pitto burgh, Pennsylvania 15213, U.S.A.
} 
The number of subjects seen in the different surveys, and the exclusions and the numbers, with the mean values for relevant parameters, of those who have been included, are listed in Table I. In order to make all the data comparable the values for F.E.V. ${ }_{0.75}$ have been converted to F.E.V. ${ }_{1}$ (McKerrow et al., 1960).

The measurements at Annandale and the Vale of Glamorgan and half those at Staveley were made by one observer

\section{Relationship of F.E.V. to Age and Height for Several Groups of Subjects}

Sources of all the published data relating the F.E.V. to height and age over a wide range that were known to us at the time of preparing this paper are listed in Table III, which also contains a summary of the criteria for selection of subjects and the techniques of the different workers. The corresponding

TABLE I.-Source of Material

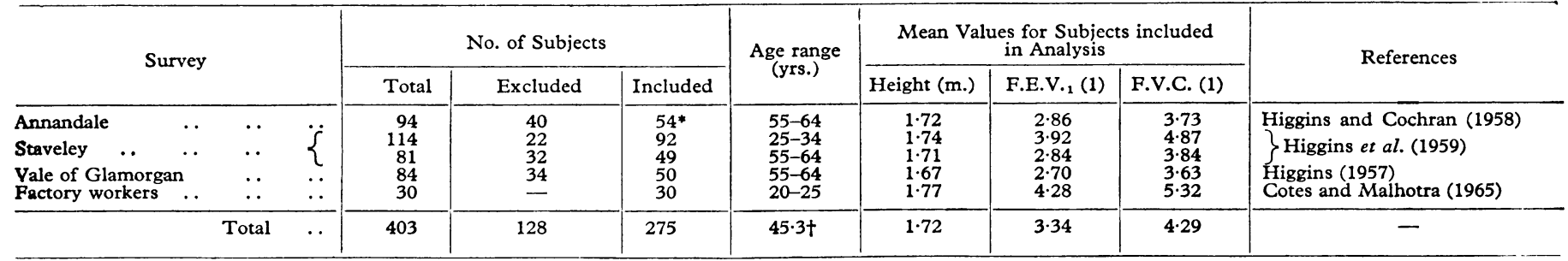

- Seven quarry workers were inadvertently included in this group. t Mean value.

(I. T. T. H.) ; the remainder were made by two others. Small inter-observer differences were observed, but these did not exert a material influence on the overall result.

In the first stages of the analysis the variability of the results attributable to differences in age, standing and sitting (or stem) height, and body weight was examined separately for the nonsmokers, and for two categories of smokers subdivided according to their consumption of tobacco. A non-smoker was defined after the manner of Doll and Hill (1950) as one who at no time in his life had smoked as much as $1 \mathrm{~g}$. of tobacco per day for one year. Light-to-moderate smokers were defined as those who smoked 1-14 g. per day (also ex-smokers), and heavy smokers as those who smoked more than $14 \mathrm{~g}$. per day. Results of the analysis have been expressed in the form of regression equations in order to permit calculation of the ventilatory capacity to be expected for people of different age and size. For the three categories of smokers the mean ventilatory capacities standardized to the average age, height, and weight of the whole group were respectively $3.40,3.16$, and 3.231 . These three values did not differ significantly, and the relations to age, height, and weight within the three groups separately were practically the same. The three groups have therefore been combined to yield the overall regressions shown in Table II.

TABLE II.-Regression Relationships with Standard Errors of Regression Coefficients $(P<0.01)$

$$
\begin{array}{ll}
\text { F.E.V.1 } & =3.46( \pm 0.40) \mathrm{Ht}-0.033( \pm 0.002) \text { age }-1.12(\mathrm{R}=0.83, \\
\text { F.V.C. } & =5.08( \pm 0.47) \mathrm{Ht}-0.032( \pm 0.002) \text { age }-3.02(\mathrm{~S}) \mathrm{R}=0.82, \\
\begin{array}{l}
\text { F.E.V./F.V.C. } \\
\times 100 \%
\end{array} & =85.35-0.169( \pm 0.03) \text { age }(\mathrm{r}=0.31, \text { S.D. } 8.26)
\end{array}
$$

Neither the substitution of stem height for standing height nor the inclusion of body weight materially improved the relationships.

regression relationships are given in Table IV and are illustrated for the ages of 20 and 60 years in Fig. 1.

TABLE IV.-Regression Relationships of F.E.V. (1 $^{1}$ B.T.P.S.*) on Age

Series

V.A., U.S.A.

Göteborg, Sweden

C.E.C.A.

Dutch foundries

Berlin, N.H., U.S.A.

P.R.U., U.K.
Relationships of F.E.V.
(Years) and Height (m.)

Regression Relationships

$3.7 \mathrm{Ht} .-0.028$ age $-1.59 \quad R=0.63$, S.D. 0.52

3.75 Ht. -0.036 age -1.09 S.D. 0.545

Ht. $^{3}\left(825.57+1.05\right.$ age -0.061 age $\left.^{2}\right) 10^{-3}+$ S.D. $10 \%$

Ht. ${ }^{2 \cdot 12} \times 10^{(0 \cdot 219-0.00425 \mathrm{age})} \mathrm{R}=0.67$

$3.6 \mathrm{Ht}$. -0.027 age $-1.65 \quad R=0.71$, S.D. 0.49

3.46 Ht. -0.033 age $-1.12 \quad R=0.83$, S.D. 0.45

* B.T.P.S. $=$ Body temperature and pressure saturated with water vapour.

t Calculated from the relationship of F.E.V./Ht. ${ }^{3}$ on age.

$\mathrm{R}$ (multiple correlation coefficient) is extent to which the data are described by the relationship. $R=1$ would indicate a perfect description, while $R=0$ would indicate that no relation exists on these data. S.D. (standard deviation) is scatter of the dat about the regression line; $68 \%$ of observations would be expected to lie within 1 S.D. and $95 \%$ within 2 S.D. On either side of the line, if for any given heigh and age the F.E.V.1 is normally distributed.

The criteria for selection of subjects for the different surveys were in general similar except for the older subjects in the European Coal and Steel Community (C.E.C.A.), among whom the scatter of the data was greater than in the younger subjects. This finding was attributed to the presence in the older group of subjects who, while they appeared healthy on routine clinical examination, would have been found to be abnormal if a more thorough examination had been carried out (Cara et al., 1961). To secure a more representative group the authors excluded from their analysis the subjects whose data deviated furthest from the mean. This procedure is likely to have contributed to the high values reported from the C.E.C.A. for the older subjects. The techniques used to analyse the data from the different surveys are all of the regression type and therefore basically similar, but they differ in that both linear and quadratic relations are reported.

In the case of the C.E.C.A. another feature which distinguishes the analysis from others is the assumption, on theoretical

TABLE III.-Studies in which the F.E.V. has bcen Related to Age and Height in Male Subjects without Overt Chest Illness

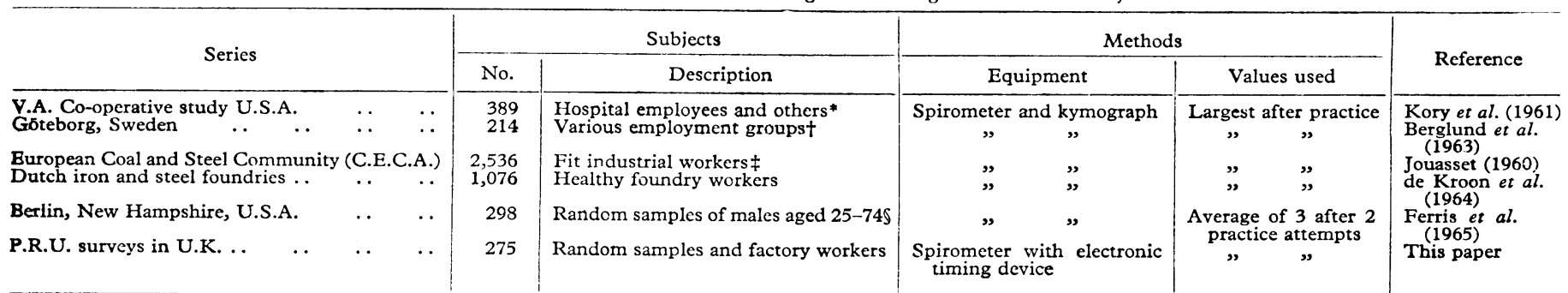

- In this study the following criteria were required for acceptance as a subject: (a) No history of chronic cardiopulmonary disease or acute cardiopulmonary disease during the six-month period preceding the testing; (b) No evidence from physical examination, chest $x$-ray film, and electrocardiogram of cardiopulmonary disease; (c) Physically and mentally capable of adequate cooperation during the tests; (d) No manifest weakness or debility which significantly limits activity; ( $e$ ) No evidence or history of disease which can be expected to affect pulmonary function (such as neuromuscular disorders or arthritis of the spine). 
grounds, of a proportionality between F.E.V., and height cubed (cf. de Kroon et al., 1964). This assumption when applied to the present data (Fig. 2) has the effect of increasing both the average slope over the physiological range of the relationship on height and the scatter about the regression line. Since it may have similarly increased the slope for the C.E.C.A. series (Fig. 1) these results are not considered further. The remaining relationships show close similarities, particularly in the regression coefficients on age and height, while there are systematic differences in the constant terms. These findings may reflect the genetic constitutions of the populations studied; alternatively, they may be due to the operation of different technical or environmental factors in subjects in whom lung function is essentially similar. In this event an improved estimate of the magnitude of the coefficient of F.E.V. on age and height may be obtained by combining the relationships.

In the present instance the procedure for combination has been applied to the linear regression relationships only, since the additional inclusions of the curvilinear relationship from the Netherlands would have required access to data which are not readily available; however, the omission is unlikely to have materially influenced the result. The new relationship is made up of those for the Veterans Administration and Berlin, New

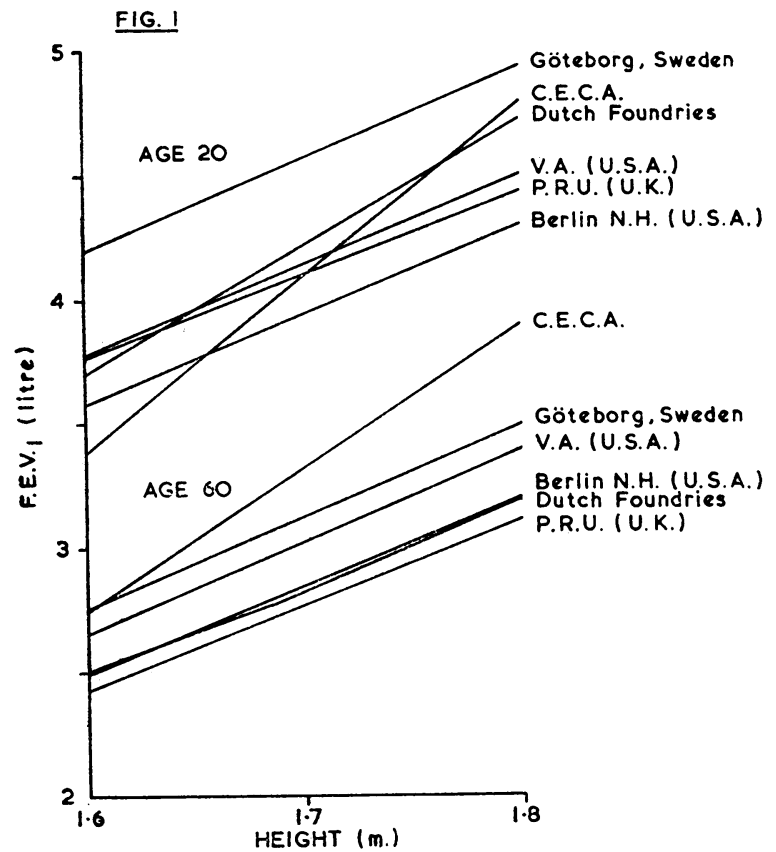

Fig. 1.-Regressions of F.E.V. on height and ages 20 and 60 years for normal males from different population surveys (see also Tables III and IV).

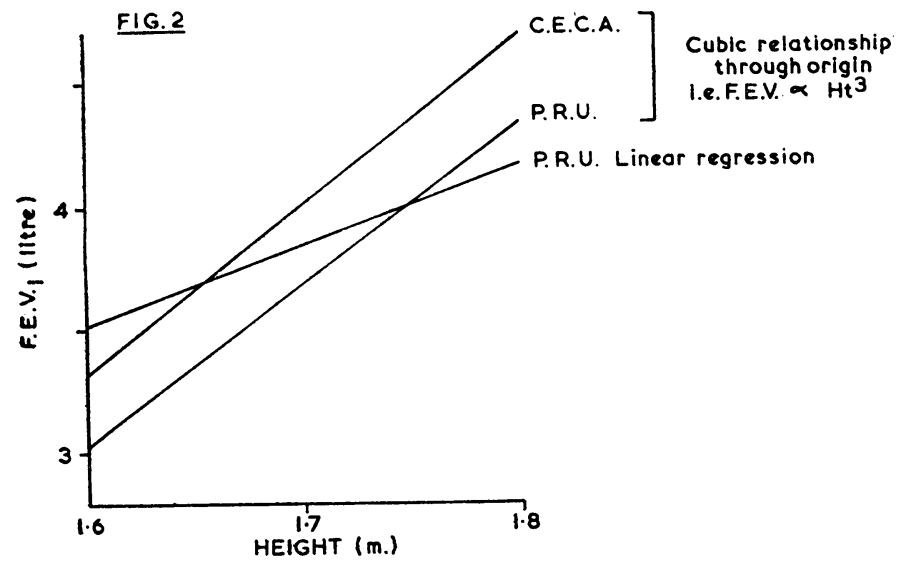

FIG, 2.-Cubic regressions through the origin of F.E.V.1 on height and FIG. 2.- Cubic regressions through the origiects. For the latter subjects age 27 rears for C.R.C.A. and P.R. . subjects. the scatter about this line is significantly greater $(\mathrm{P}<0.0$
the Hnear regression, which is also shown.
Hampshire, U.S.A.; Göteborg, Sweden ; and the Pneumoconiosis Research Unit (P.R.U.) in the U.K. The relative contributions of these data have been weighted in inverse proportion to the scatter (variance) about the regression line; this may be written in the form of an equation as follows:

$$
\text { F.E.V., }=3.62 \mathrm{Ht}-0.031 \text { age }-1.41 \text { (S.D.>0.5). }
$$

The relationship is illustrated graphically in Fig. $3 .^{1}$ In relation to the data in Fig. 1, the new regression at age 20 years coincides with that for the Veterans Administration; at age 60 years it is very similar to that for Berlin, New Hampshire.

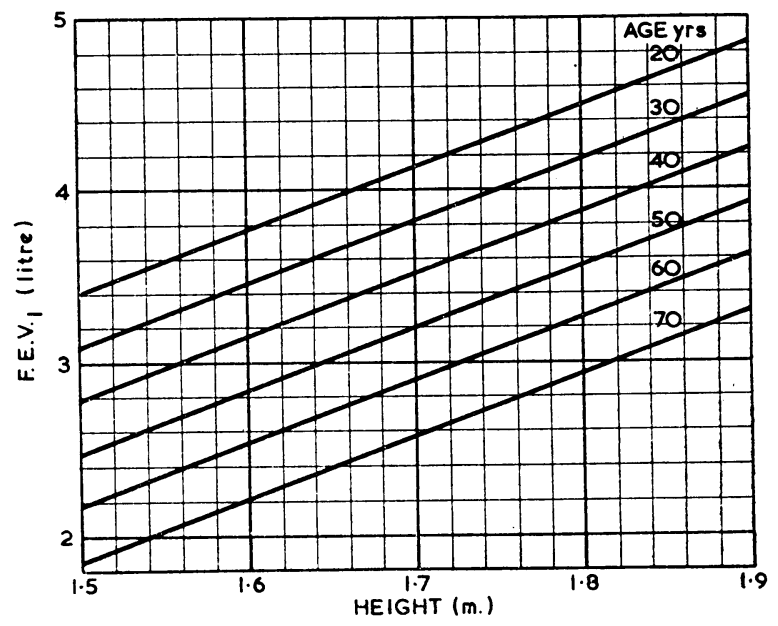

FIG. 3.-Combined regression of F.E.V., on height and ages 20 to 70 years for normal male subjects

\section{Discussion}

The subjects for this study are predominantly healthy white adult males who are free from chest illness of the type defined and not selected on account of their physique; other ethnic groups may also be represented but in numbers too small to influence the result materially. The analysis suggests that for these subjects the F.E.V..$_{1}$ is related to age and height in an essentially uniform manner throughout N.W. Europe and N. America. The relationship can be described with reasonable precision by a linear regression equation, though there is no a priori reason why it should have this form. Superimposed on the common relationship there are regional and other differences, which may be partly related to smoking habits, climate, and the level of atmospheric pollution.

The regression coefficient on height is relatively constant for the different populations; this factor is likely to be determined mainly by constitutional factors, and, since the subjects are fully grown, is probably relatively independent of the environment. The environment may influence the reduction in height which occurs with increasing age, but the effect is likely to be small. The regression coefficient on age is susceptible to the influence of smoking (Higgins and Oldham, 1962) and probably other factors, including atmospheric pollution, which exert a cumulative effect more pronounced in some environments than in others. However, the importance of these factors is minimized by limiting the analysis to subjects with apparently healthy lungs. For both the P.R.U. data from the United Kingdom and the two series quoted from the U.S. this restriction has the effect of raising the mean values in the smokers towards those of the non-smokers. However, other workers, including Wilson et al. (1960) and Olsen and Gilson (1960), have observed low values for the F.E.V. in some categories of smokers who have no evidence of chronic non-specific lung disease. These apparently discrepant findings are reconciled in the observation of Ferris

1 Enlarged copies of this diagram may be obtained from the Librarian Pneumoconiosis Research Unit, Llandough Hospital, Penarth Glamorgan. 
et al. (1965) that the smokers have both higher values in the younger age groups and a steeper decline with age than the non-smokers.

The constant term of the regression is more variable between the different series than the coefficients on height and age. Part of this is technical-for example, Ferris et al. find an average difference of $0.164 \mathrm{l}$. between the maximum F.E.V. and the mean of the last three out of a total of five determinations. The use of equipment having different flow characteristics, and calibration errors, may also have contributed to the systematic differences observed. Part is due to environmental factorsfor example, smokers often achieve an increase in F.E.V. when they give up smoking, and a reduction in atmospheric pollution may be expected to have a similar beneficial effect (cf. Holland and Reid, 1965).

The role of constitutional factors in determining the F.E.V. may be defined with greater certainty when more data are available for rigorous statistical analysis. This may come through the International Biological Programme and the activities of the International Labour Office and World Health Organization. Knowledge of the effect of environmental factors will similarly come from the many epidemiological surveys now in progress. Meanwhile on account of its broad basis the present relationship may be of use to those wishing to compare their average results with those of others. For example, it is of interest to us that the mean value for the F.E.V. ${ }_{1}$ in men aged 55-64 years on the island of Bornholm (Olsen and Gilson, 1960 ) is in exact agreement with the present finding.

The prediction of expected values for individuals, on account of variability between subjects, is less exact than for groups; it is best done by reference to the measured values for a representative sample drawn from the community in question. Where such data are not available the present relationship may be substituted, either as it stands or, if there are data available for one age-and-height group, after adjustment to the constant term. For example, in the case of Bornholm the only available data are for the 55-64 age group, and these are in close agreement with the overall relationship: the latter is therefore the best available estimate for the other age groups. If the average value in the selected group had been $x \mathrm{ml}$. below predicted, then for application to the population this amount should be subtracted from that given by the relationship. However, the extent to which it is justifiable to extrapolate in this way will vary from one community to another, and should be submitted to practical confirmation at the first opportunity. Without more evidence extrapolation is not justifiable for other ethnic groups in whom lower values for the F.E.V. have been reported: these include the inhabitants of the subcontinent of India (Rao et al., 1961 ; Cotes and Malhotra, 1965), the Maori of New Zealand (Glass, 1962), and members of some African races (Paul et al., 1960 ; Gilson et al., 1962). These racial differences have still to be explored.

\section{Summary}

A linear regression of forced expiratory volume (F.E.V..$_{1}$ ) on age and height is reported for 275 healthy male subjects living in the United Kingdom. The regression coefficients are similar to those reported from other countries in N.W. Europe and $\mathrm{N}$. America. The equations have therefore been combined to yield the following overall relationship, which may be of use for predicting average normal values:

F.E.V $\cdot_{1}=3.62 \mathrm{Ht}(\mathrm{m})-$.0.031 age (years) -1.41 (S.D.>0.5) 1 B.T.P.S.

The limitations to the use of this relationship are discussed.

We are indebted to Miss A. Hart, Mrs. C. John, and Miss C. Wilton for technical assistance.

\section{REFERENCES}

Berglund, E., Birath, G., Bjure, J., Grimby, G., Kjellmer, I., Sandqvist, L., and Söderholm, B. (1963). Acta med. scand., 173, 185. Cara, M., Sadoul, P., and Bolt, W. (1961). C.R. Soc. Biol. (Paris), 155,

Cotes, J. E., and Malhotra, M. S. (1965). F. Physiol. (Lond.), 177, 17-18P.

de Kroon, J. P. M., Joosting, P. E., and Visser, B. F. (1964). Arch. Mal.

Doll, R.of., 25, 17. and Hill, A. B. (1950). Brit. med. F., 2, 739.

Doll, R., and Hill, A. B. (1950). Brit. med. 7., 2, 739. resp. Dis., 91,252 .

Gilson, J. C., Stott, H., Hopwood, B. E. C., Roach, S. A., McKerrow, C. B., and Schilling, R. S. F. (1962). Brit f. industr. Med., 19, 9.

Glass, W. I. (1962). N.Z. med. F., 61, 433.

Higgins, I. T. T. (1957). Brit. med. Э., 2, 1198. (1959). Ibid., 1, 325 . and Cochran, J. B. (1958). Tubercle (Lond.), 39, 296

Cochrane, A. L., Gilson, J. C., and Wood, C. H. (1959). Brit. ₹. industr. Med., 16, 255. and Oldham, P. D. (1962). Ibid., 19, 65.

- Cochrane, A. L., and Gilson, J. C. (1956). Brit. med. f., 2,

Holland, W. W., and Reid, D. D. (1965). Lancet, 1, 445.

Jouasset, D. (1960). Poumon, 16, 1145.

Kory, R. C., Callahan, R., Boren, H. G., and Syner, J. C. (1961). Amer. भ. Med., 30, 243 .

McKerrow, C. B., McDermott, M., and Gilson, J. C. (1960). Lancet, 1, 149.

Medical Research Council (1960). Brit. med. 7., 2, 1665.

Olsen, H. C., and Gilson, J. C. (1960). Ibid., 1, 450

Paul, R., Fletcher, G. H., and Addison, G. (1960). Med. Proc., 6, 69.

Rao, M. N., Sen, G. A., Saha, P. N., and Devi, A. S. (1961). Indian Coun. med. Res. spec. Rep. Sor., No. 38.

Wilson, R. H., Meador, R.S., Jay, B. E., and Higgins, E. (1960). Ners Engl. F. Med., 262, 956.
Increasing attention is being focused on the "false-positive" Phenistix test (Hudson et al., 1963 ; Coffey, 1964). The following case of histidinaemia was detected as a result of this. Ghadimi et al. (1962) first described a case of histidinaemia and demonstrated an excess of histidine in plasma and urine. Subsequently Auerbach et al. (1962) showed the defect to be due to a deficiency of the enzyme histidase (Fig. 1), and agreed with Ghadimi et al. that the positive reaction with ferric chloride

* Paediatric Registrar, Plymouth General Hospital.

† Biochemist, Plymouth General Hospital. resulted from the presence of imidazole pyruvic acid in the urine.

That there are no consistent clinical findings in this disorder is agreed. Initially, cases were reported of patients who were mentally normal but had a speech defect (Auerbach et al., 1962 ; La Du et al., 1963a, 1963b ; Woolf, 1965). Subsequently the cases of severely physically and mentally handicapped patients who suffered from intercurrent infections and convulsions were reported (Davies and Robinson, 1963 ; Holton et al., 1964). The present report concerns an older child who was 